\title{
A'uwẽ (Xavante) Hunting Calls: A Vocal Repertoire for Ethnozoological Communication and Coordination in the Brazilian Cerrado
}

\author{
James R. Welch ${ }^{1^{*}}$ \\ ${ }^{1}$ Escola Nacional de Saúde Pública, Fundação Oswaldo Cruz, Rio De Janeiro, Brazil. \\ *welch@ensp.fiocruz.br
}

\begin{abstract}
Group hunting is a productive subsistence activity for many Indigenous peoples with adequate access to territorial and game resources. A'uwẽ (Xavante) group hunts can involve large numbers of individuals coordinating group hunting efforts over large areas. A'uwẽ group hunting and hunting with fire are sophisticated endeavors requiring years of preparation, ample discussion, and post-hunt analysis. Their hunting calls are stylized expressions following established vocal conventions to communicate complex information over long distances between hunters in order to follow, flush, dispatch, and carry game. This discussion is based on recordings provided by the late A'uwẽ elder and leader Tsidowi Wai'adzatse' in 2006. He wished that the calls be documented so younger individuals will have means to recall them. I address how Indigenous A'uwẽ hunters in the Brazilian cerrado communicate over long distances with hunting calls that encode rich ethnozoological information. After introducing the topic and context, I begin with a presentation of five ethnozoological calls Tsidowi demonstrated, which he considered the complete repertoire of A'uwẽ hunting calls. Following these short descriptions, I discuss some of the vocal qualities observed in the calls (without conducting a full linguistic analysis), the ethnozoological information they encode, and their prospects for continued use into the future within the context of group hunting with fire.
\end{abstract}

Received March 30, 2020

OPEN ठACCESS

Accepted May 4, 2020

DOI 10.14237/ebl.11.1.2020.1688

Published June 4, 2020

Keywords Ethnozoology, Food acquisition, Sound ethnobiology, Indigenous peoples, South America

Copyright (C) 2020 by the author(s); licensee Society of Ethnobiology. This is an open-access article distributed under the terms of the Creative Commons Attribution-NonCommercial 4.0 International Public License (https://creativecommons.org/licenses/by-nc/4.0), which permits non-commercial use, distribution, and reproduction in any medium, provided the original author and source are credited.

Supplementary Files available at https://doi.org/10.14237/ebl.11.1.2020.1688

\section{Introduction}

Group hunting is a productive subsistence activity for many Indigenous peoples with adequate access to territorial and game resources. Among the A'uwẽ (Xavante) of Central Brazil, ritualized hunting of game animals has been documented since nearly two centuries ago (Pohl 1837). Multiple early accounts and my own more recent research associate burning the landscape with large group hunts involving upwards of 50 to 75 hunters at any given time (Welch 2014). Group hunting is usually conducted using fire as a tool, although I have accompanied several group hunts that did not employ burning the vegetation. The use of fire is determined by diverse factors, including the availability of hunting grounds that have been left unburnt for appropriate lengths of time, which range from one to three or four years, depending on the vegetation type (Welch 2014). Even when fire is not employed, A'uwẽ group hunts can involve large numbers of individuals coordinating group hunting efforts over large areas (Welch 2015). The collaborative techniques employed with and without fire are similar. Individual and small group hunting is also practiced, although less so in recent decades. Today, hunting is accomplished with firearms by adults and clubs by youth, as the last bow and arrow hunters died in recent years. The yields are shared with hunting companions according to strict protocols (Welch 2014) and delivered to hunters' wives and mothers-in-law for roasting and further sharing according to A'uwẽ notions of food reciprocity.

Group hunts are used to acquire any kind of desirable game, not just those addressed in the 
hunting calls presented here. Whereas large social animals, such as white-lipped peccary (Tayassu pecari), are especially desirable because large amounts of game meat can be acquired in short periods of time, other preferred animals are also killed, such as deer (Blastocerus dichotomus, Mazama americana, Mazama gouazoubira, and Ozotoceros bezoarticus), tapir (Tapirus terrestris), giant anteater (Myrmecophaga tridactyla), collared peccary (Pecari tajacu), and smaller animals (e.g., ground birds, hystricognaths, armadillos, and tortoises). These hunting practices have been criticized for causing animal depopulation and deforestation, but available evidence suggests the opposite: A'uwẽ group hunting and hunting with fire do not measurably impact game populations (Prada 2001; Villalobos 2002) and have neutral to positive effects on vegetation cover (Welch et al. 2013).

\section{Group Hunting in A'uwẽ Society}

Hunting throughout Amazonia has been and remains important not just for subsistence, but sociality, reciprocity, and socialization. A'uwẽ group hunting and hunting with fire are sophisticated endeavors requiring years of preparation, ample discussion, and post-hunt analysis (Welch 2014, 2015). The kind of preparation required to transform youth into group hunters is culturally defined as a slow process initially involving only indirect participation by pre-initiates (wapte) of approximately adolescent age in hunting activities in order to permit them time to observe experienced hunters. Slightly older youth in the novitiate men's age category also listen during men's meetings and thereby gain knowledge of what is involved in planning a group hunt and the lessons emerging from elders' post-hunt critiques. The first event in the long series of rituals that comprise the A'uwẽ rites of passage into adulthood is a weeks-long ritualized group hunt with fire, during which preinitiates accompany their mentors and elder hunters, often for the first time, in order to observe hunting, tend camp, and carry game animals and thereby begin the process of becoming hunters by imitating adult hunting behaviors (Welch 2015). This educational process reflects and contributes to what is considered the good and proper social upbringing of young men in A'uwẽ society, which will transform them into respectful and responsible husbands and fathers. Thus, collective action required for a group hunt reaffirms social ties, interdependence, and provides contexts for leadership.

$$
\text { Additionally, large prey animals are shared, }
$$

contributing to the celebration of many of life's important events as well as mitigating subsistence. Large game animals are usually hunted in groups in order to acquire large quantities of meat to give as gifts for weddings and different kinds of rites of passage (Welch 2014). In all cases, they are ultimately repartitioned and distributed to the entire village. Distributions considered satisfactory should be composed only of large game animals (mainly peccaries, tapir, deer, and giant anteaters) and be sufficiently ample for everyone to partake and thereby participate in the celebratory mood. Smaller game animals killed during group hunts are taken home by the individual hunters who dispatched them for domestic consumption and sharing.

Group hunting strategy is especially challenging to ascertain as an observer, as it is learned through observation and imitation and is rarely articulated explicitly in A'uwẽ discourse, except during post-hunt analysis conversation. In fact, certain aspects of ritualized interaction between hunters are explicitly hidden from young hunters so that they might discover them on their own through well-intentioned ridicule, a learning technique considered more effective than overt instruction (Welch 2014). Hunting strategy involves diverse dimensions deriving from the need for coordination, as previously described for a 2005 hunt involving fire: "Combining intimate knowledge of game behavior and the local terrain with tracking skills and a complex set of hunting calls, they efficiently articulated their efforts throughout an area measuring approximately $60 \mathrm{~km}^{2}$ " (Welch 2015:196).

The coordination and communication involved in group hunting pertain to some but not all hunting activities, and individual and small group hunting requires fewer coordination tools, especially because participants are not dispersed throughout large territories. During group hunts, including those employing fire, coordination is especially important in locating and reaching game animals, scattering or driving them towards hunters awaiting at a distance, and carrying them back from the hunt. During individual hunts, collective action is most important for digging burrowing animals out of the ground and carrying large animals back to the village.

\section{Hunting Calls}

The hunting calls I mention are tools unlike those used by contemporary sport hunters in the United States, which are noisemakers intended to imitate animal calls and thereby attract animals to the hunter. 
They are also unlike Umutina hunting calls designed to imitate and attract animals, such as birds or monkeys, in the Brazilian Amazon (Schultz 1953). They are more appropriately compared with communication between hunters by whistling documented in lowland South America. The Aché of Paraguay whistle to one another to call for and respond to the need for help to dig out a paca burrow or when a single hunter encounters a group of social animals best hunted by a group (Hill and Hawkes 1983). Communication by whistling sentences is used by hunters to communicate complex ideas among the Karitiana and Gavião in the Brazilian Amazon (Moore and Meyer 2014). A'uwẽ calls are also comparable to hunting horn calls used since medieval times in Europe. The hunting horn is among the earliest lip-reed instruments, used by hunting parties to coordinate tracking and to signal in which direction the game would flee (Heater 1995). With time, playing the hunting horn became an essential skill and a symbolic mark of nobleman status, while hunting horns eventually became a musical instrument used in orchestras. Similar to hunting horn calls and Indigenous hunting whistling, A'uwẽ hunting calls are a stylized expression following established vocal conventions to communicate complex information over long distances between hunters in need of or able to provide assistance. Also, like Indigenous whistling and hunting horn calls, the information encoded in A'uwẽ hunting calls is ethnozoological.

This discussion is based on recordings provided in 2006 by the late A'uwẽ elder and leader Tsidowi Wai'adzatse'. He wished that the calls be documented so younger individuals will have means to recall them. His desire to preserve them speaks to their cultural value beyond their use as mere hunting tools, but also to their importance as symbolic markers of ethnic identity. Similar to the process by which hunting horn call competency came to signify noble status among Welsh male youth (Heater 1995), the ability to effectively vocalize hunting calls during group hunts has become a marker of A'uwẽ traditionalism, hunting competency, and ability to provide healthful food for one's family. Thus, it is one of the hunting skills a young hunter learns before he is allowed to carry a bow and arrow or firearm during a hunt. Children practice hunting alone with play bows and arrows, but it is only later in life as pre-initiates that they usually begin learning during group hunts by tending camp and carrying game meat, while novitiate adults accompany the hunt with clubs rather than firearms or bows. These youth learn by accompanying elder hunters, who allow them to make hunting calls when appropriate situations arise. Thus, by the time they are mature men, they should be prepared to hunt alone or lead group hunts and use hunting calls appropriately.

In this paper, I address how Indigenous A'uwẽ hunters in the Brazilian cerrado communicate over long distances with hunting calls that encode rich ethnozoological information. I begin with a presentation of five ethnozoological calls demonstrated by Tsidowi, which he considered the complete repertoire of A'uwẽ hunting calls (Recordings 1-5). Each short description is accompanied by an audio file which may be used for noncommercial purposes if properly cited according to the Creative Commons Attribution-NonCommercial 4.0 International (CC BY-NC 4.0) license. Following these short descriptions, I discuss some of the vocal qualities observed in the calls (without conducting a full linguistic analysis), the ethnozoological information they encode, and their prospects for continued use into the future.

Please note that all call names are comprised of the name of the animal to which it pertains followed by the term for call ('mäböri). As there may be more than one call for the same animal, each carrying a different message, there may be more than one call with the same call name and one call with more than one name. Recordings 1-5 are available as Electronic Supplementary Material with this article.

Recording 1

Call name: ubömãä̈ri

Animal: White-lipped peccary (Tayassu pecari)

Purpose: Come assist in chase

Context: This is the first of two uhömaahöri (whitelipped peccary calls). When a tracker spots a band of peccary and needs help to give chase, he does not begin pursuit immediately. Instead, he removes himself to a safe distance where his calls will not alert the animals but will travel far, such as in a tree several hundred meters from the waterway where the white-lipped peccaries were observed. This call for assistance is repeated loudly and continually for as long as it takes for enough people to arrive, which may take some time if people are dispersed at a 
distance. Once enough people have gathered, the calls are discontinued, and pursuit begins. If enough time has passed, it is possible that the peccary band has moved locations and it may be necessary to relocate it by tracking recent movements.

Recording 2

Call name: utö'mãhöri

Animal: Tapir (Tapirus terrestris)

Purpose: Help carry animal

Context: This is the first of two utö'mãhöri (tapir calls). This recording includes the hunter's calls and responses. The caller has killed a tapir and requires help carrying the meat because it is too large an animal for one person to carry alone. After the initial call soliciting assistance, the responder indicates he is on his way. He expects to be paid with the head of the animal he helps carry. Usually younger men respond because after the hunt they are expected to give presents of meat to their parents-in-law, but they may not have killed their own game.

Recording 3

Call name: pati'mãböri and poze'mãhöri

Animal: Giant anteater (Myrmecophaga tridactyla) and marsh deer (Blastocerus dichotomus)

Purpose: Help carry animal

Context: This call may be used for either giant anteater or marsh deer. The caller has killed an animal and requires help carrying the meat because the animal is too large for one person to carry alone.

Recording 4

Call name: warã wãwe'mãhöri

Animal: Giant armadillo (Priodontes maximus)

Purpose: Help digging animal out of its hole

Context: The caller has come across a giant armadillo holed up underground. Help is needed to dig out the animal.

Recording 5

Call name: uhö'mãhöri and utö'mãhöri (name depends on which animal is hunted)
Animals: White-lipped peccary (Tayassu pecari) and tapir (Tapirus terrestris)

Purpose: Coordinate chase of fleeing animals

Context: This call may be used for either whitelipped peccary or tapir and is therefore the second uhö'mähöri call and the second utö'mäböri call. This recording includes alternating hunting calls and regular lexical vocal communication. This call is used when additional hunters are required to help give chase to a white-lipped peccary or tapir that escaped a smaller group of hunters. Specifically, help is needed by positioning hunters at specific strategic positions. In this example, the caller tells other hunters that: (1) a band of peccary ran downriver; (2) then escaped and ran upriver; (3) is now running toward another group of hunters that can be positioned to dispatch them, and (4) whoever responds first will share the meat and everyone will eat well today.

\section{Discussion}

A recent publication calling for renewed emphasis on the ethnobiology of sound (Wright 2017) was partially answered by a special issue of the Journal of Ethnobiology entitled "Ethnobiology through Song" (FernándezLlamazares and Lepofsky 2019). An ethnobiology of sound should, however, contemplate yet more diverse dimensions of the "soundscape." The A'uwẽ soundscape includes diverse genres of vocal expressions, ranging from ritualized forms of discourse to wails and songs (Graham 1984, 1986, 1995). Hunting calls should also be added to this list.

In addition to this repertoire of five hunting calls, Tsidowi also demonstrated two other calls that are only tangentially related to hunting. These were a call for help in the event of an accident, such as a snakebite, and call advising that enemies have been spotted. These additional calls are not presented in this article. The existence of only five hunting calls pertaining to five major game animals begs the question of why other game animals lack hunting calls. Unlike many other Amazonian societies that preferentially hunt small mammals and birds (Milton et al. 1991), the A'uwẽ prefer to hunt large game mammals because, from their point of view, they are tastier and less encumbered by the dietary restrictions characteristic of small game animals, which are 
believed to be dangerous for people of reproductive age and to slow down runners and make younger adults lazy (Leeuwenberg and Robinson 2000; Maybury-Lewis 1967; Welch 2014). Notably, they do not eat monkeys, which are a common game animal among many other Amazonian societies. Smaller deer (Mazama americana, Mazama gouazoubira, and Ozotoceros bezoarticus) and collared peccary are among the preferential game animals without hunting calls. Smaller deer were reported to not require hunting calls because one person can carry the entire animal without assistance and because they are too alert, making noisy calls disadvantageous. This is because hunting calls are made as loud as possible, at the top of one's lungs, in order to reach people as far as away as possible. Collared peccaries do not require calls because they are small enough to be carried and because, according to the A'uwẽ, they are largely solitary in the cerrado, making coordinated group hunting unnecessary (although they will be killed during group hunts if encountered). Additionally, the giant anteater has no call to chase because, simply, the A'uwẽ say they do not run.

With the exception of portions of Recording 5, the other call recordings demonstrate that Xavante hunting calls are largely what linguists might call "non -verbal" or "non-lexical" vocal expressions because they do not contain words (Anikin et al. 2018). This interpretation would incorrectly align them with emotional vocalizations such as laughs, cries, and screams. They might also be called "vocables," sounds with no lexical meanings, which would interestingly align them with Navajo ceremonial singing (Frisbie 1980) and the confederate rebel yell (Read 1961). However, my central argument is that A'uwẽ hunting calls carry specific meanings, which leads us to the conclusion that they should instead be considered verbal or lexical vocal expressions, much as is Bororo whistling (Aytai 1979) and the previously mentioned hunting communication by whistling among the Aché, Karitiana, and Gavião (Hill and Hawkes 1983; Moore and Meyer 2014). I make this preliminary assertion based on an ethnographic reading of their contents without a detailed linguistic analysis of their composition.

Considering the data presented here, I identify eight kinds of explicit or implicit ethnozoological information encoded in A'uwẽ hunting calls, grouped into three categories (Table 1).

For experienced hunters, these messages would be relatively simple to communicate using regular spoken language, but they would be less effective in terms of carrying long distances and succinctness. Recording 5 is less succinct than the others, but this is mainly because it includes the responder's regular lexical speech. The portions of Recording 5 made by the caller contain an astonishingly complex set of information considering its brevity, namely, the animal taxon (white-lipped peccary), three animal movements (ran downriver, then ran upriver, then ran toward another group of hunters), the strategy of positioning hunters in the direction towards which the peccaries are running, and the reward of sharing the meat and

Table 2 Eight kinds of explicit or implicit ethnozoological information encoded in A'uwẽ hunting calls.

\begin{tabular}{|c|c|c|}
\hline $\begin{array}{l}\text { Ethnozoological information encoded in A'uwẽ } \\
\text { hunting calls }\end{array}$ & Explicit or implicit & Category \\
\hline Ethnotaxon of game animal spotted or killed & explicit & characteristics of game animal \\
\hline Size of animal & implicit & characteristics of game animal \\
\hline Need for assistance & explicit & kind and quality of hunting assistance needed \\
\hline Urgency & explicit & kind and quality of hunting assistance needed \\
\hline $\begin{array}{l}\text { Animal's location and direction; how it got there; } \\
\text { where hunters should be positioned }\end{array}$ & explicit & kind and quality of hunting assistance needed \\
\hline $\begin{array}{l}\text { Intention to share meat; sense of happiness and } \\
\text { responsibility }\end{array}$ & implicit & social relations involved in providing assistance \\
\hline Intention to assist; desire to receive compensation & explicit & social relations involved in providing assistance \\
\hline $\begin{array}{l}\text { Kinship ties to hunter calling for help; part of } \\
\text { animal desired in compensation }\end{array}$ & implicit & social relations involved in providing assistance \\
\hline
\end{tabular}


contributing to community well-being because everyone will eat well.

\section{Conclusions}

Tsidowi recorded these calls because he believed they were in danger of being forgotten and lost to future A'uwẽ hunters. Indeed, as fewer A'uwẽ men choose to hunt to feed their families, there is a risk of loss of cultural ecological information, including hunting calls. In my observation, as younger people choose to hunt less, group hunts employing fire are the only kind of hunt that essentially all young and adult males continue to participate in, making it the most important venue for them to learn hunting calls and other forms of hunting tools and collaboration skills (Welch 2014). Thus, hunting with fire is becoming a symbol of A'uwẽ identity and an indispensable opportunity for youth to learn about not only the process of hunting, but also the kinds of collectivity, respect, and reciprocity it entails. This knowledge and these values help enable people to make a living as well as making life meaningful. My evaluation of their current status is that Recordings 1-4 continue to be used widely, even by infrequent hunters, but that Recording 5 has become specialized knowledge of experienced hunters. Some infrequent hunters, who prefer to participate only in group hunts employing fire, may respond to hunting calls but not have opportunities to produce them. Women, who do not hunt large game, are also familiar with at least the first four calls through exposure near villages or gardens or while travelling throughout the territory with men. These recordings have been returned to the community so that everyone, including young apprentice hunters, may hear them, imitate them, and put them into use according to the culturally appropriate A'uwẽ method of learning to hunt.

\section{Acknowledgments}

I thank the late Tsidowi Wai'adzatse' for demonstrating the hunting calls and Huatá Wameru Otomopá for interpreting the calls and their hunting contexts. I also thank all A'uwẽ residents of Pimentel Barbosa, Etênhiritipá, and Novo Paraíso villages for their consistent support of our research collaboration. Carlos Coimbra and anonymous reviewers made substantial comments that improved the quality of this paper.

\section{Declarations}

Permissions: This study was conducted during fieldwork with permissions from the Tulane University Institutional Review Board, the Comissão Nacional de Ética em Pesquisa, and the Fundação Nacional do Índio. It was registered in the Brazilian Sistema Nacional de Gestão do Patrimônio Genético e do Conhecimento Tradicional Associado (SisGen) under Registry Number ABDA88D.

Sources of funding: Fieldwork was supported by the Fulbright Commission (DDRAF no. P022A040016) and the Conselho Nacional de Desenvolvimento Científico e Tecnológico (CNPq 422844/2016-0).

Conflicts of Interest: None declared.

\section{References Cited}

Anikin, A., R. Bååth, and T. Persson. 2018. Human Non-Linguistic Vocal Repertoire: Call Types and Their Meaning. Journal of Nonverbal Behavior 42:5380. DOI:10.1007/s10919-017-0267-y.

Aytai, D. 1979. A Linguagem de Assobio Dos Índios Bororo e Karajá. Publicações do Musen Municipal de Paulinia 7:1-23.

Fernández-Llamazares, Á., and D. Lepofsky. 2019. Ethnobiology through Song. Journal of Ethnobiology 39:337-353. DOI:10.2993/0278-0771-39.3.337.

Frisbie, C. J. 1980. Vocables in Navajo Ceremonial Music. Ethnomusicology 24:347-392. DOI:10.2307/851149.

Graham, L. R. 1984. Semanticity and Melody: Parameters of Contrast in Shavante Vocal Expression. Latin American Music Review 5:161-185.

Graham, L. R. 1986. Three Modes of Xavante Vocal Expression: Wailing, Collective Singing, and Political Oratory. In Native South American Discourse, edited by J. Sherzer and G. Urban, pp. 83-118. Mouton de Gruyter, Berlin, Germany.

Graham, L. R. 1995. Performing Dreams: Discourses of Immortality among the Xavante of Central Brazil. University of Texas Press, Austin, TX.

Heater, E. M. 1995. Early Hunting Horn Calls and Their Transmission: Some New Discoveries. Historic Brass Society Journal 7:123-141. 
Hill, K., and K. Hawkes. 1983. Neotropical Hunting among the Aché of Eastern Paraguay. In Adaptive Responses of Native Amaronians, edited by R. B. Hames and W. T. Vickers, pp. 139-188. Academic Press, New York.

Leeuwenberg, F. J., and J. G. Robinson. 2000. Traditional Management of Hunting by a Xavante Community in Central Brazil: The Search for Sustainability. In Hunting for Sustainability in Tropical Forests, edited by J. G. Robinson and E. L. Bennett, pp. 375-394. Columbia University Press, New York.

Maybury-Lewis, D. 1967. Akwẽ-Shavante Society. Clarendon Press, Oxford, United Kingdom.

Milton, K., C. D. Knight, I. Crowe, E. M. Widdowson, A. Whiten, and Q. Bone. 1991. Comparative Aspects of Diet in Amazonian ForestDwellers. Philosophical Transactions of the Royal Society of London. Series B: Biological Sciences 334:253-263. DOI:10.1098/rstb.1991.0114.

Moore, D., and J. Meyer. 2014. The Study of Tone and Related Phenomena in an Amazonian Tone Language: Gavião of Rondônia. Language Documentation 8:24.

Pohl, J. E. 1837. Reise im Innern von Brasilien. Anton Strauss, Vienna, Austria.

Prada, M. 2001. Effects of Fire on the Abundance of Large Mammalian Herbivores in Mato Grosso, Brazil. Mammalia 65:55-61.
Read, A. W. 1961. The Rebel Yell as a Linguistic Problem. American Speech 36:83-92. DOI:10.2307/453841.

Schultz, H. 1953. Vinte e Três Índios Resistem à Civilização. Edições Melhoramentos, São Paulo, Brazil.

Villalobos, M. P. 2002. Efeito de Fogo e Da Caça Na Abundância de Mamiferos Na Reserva Xavante Do Rio Das Mortes, MT, Brasil. Doctoral Dissertation, Universidade de Brasília, Brasília, Brazil.

Welch, J. R. 2014. Xavante Ritual Hunting: Anthropogenic Fire, Reciprocity, and Collective Landscape Management in the Brazilian Cerrado. Human Ecology 42:47-59. DOI:10.1007/s10745-0139637-1.

Welch, J. R. 2015. Learning to Hunt by Tending the Fire: Xavante Youth, Ethnoecology, and Ceremony in Central Brazil. Journal of Ethnobiology 35:183-208. DOI:10.2993/0278-0771-35.1.183.

Welch, J. R., E. S. Brondízio, S. S. Hetrick, and C. E. A. Coimbra Jr. 2013. Indigenous Burning as Conservation Practice: Neotropical Savanna Recovery amid Agribusiness Deforestation in Central Brazil. PLOS ONE 8:e81226. DOI:10.1371/journal.pone.0081226.

Wright, C. C. 2017. Towards an Interdisciplinary Focus on Sound in Ethnobiology Research. Ethnobiology Letters 8:58-60. DOI:10.14237/ ebl.8.1.2017.788. 